\title{
Utilization of free amino acids related to energy metabolism of developing eggs and larvae of lemon sole Microstomus kitt reared in the laboratory
}

\author{
Ivar Rønnestad ${ }^{1}$, Roderick Nigel Finn ${ }^{1}$, Erick P. Groot ${ }^{2}$, Hans Jørgen Fyhn ${ }^{1}$ \\ ${ }^{1}$ Zoological Laboratory, University of Bergen, Allégt. 41, N-5007 Bergen, Norway \\ ${ }^{2}$ Dept of Animal Science, University of British Columbia, 2357 Main Mall, Vancouver, British Columbia, Canada V6T 134
}

\begin{abstract}
Eggs and larvae of lemon sole Microstomus kitt Walbaum were reared in the laboratory $\left(7.2{ }^{\circ} \mathrm{C}, 34 \%\right.$ salinity, no supply of external food) and sampled regularly for measurement of oxygen uptake, ammonia excretion, contents of free amino acids (FAA), protein, total ammonia, and yolksac

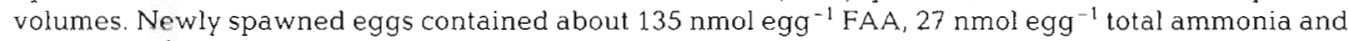
$32 \mu \mathrm{g} \mathrm{egg}{ }^{-1}$ protein. Serine, leucine, alanine, lysine, valine and glutamic acid were most abundant in the egg FAA pool. No significant changes occurred in the pool size prior to epiboly, but about $75 \mathrm{nmol}$ ind ${ }^{-1}(56 \%)$ disappeared prior to hatching and about $15 \mathrm{nmol}$ remained at final yolk absorption (Days 22 to 23). The yolk volume was linearly correlated to content of FAA. The combined data suggest that, after epiboly, increasing amounts of FAA enter the embryo from the yolk and are utilized both for energy and protein synthesis. FAA account for $60 \%$ of the aerobic energy dissipation $9 \mathrm{~d}$ after fertilization, increasing to about $100 \%$ at the time of hatching. Amino acids from protein seem to be recruited for energy dissipation after hatching. At the presumed time for first feeding lemon sole larvae derive about $20 \%$ of aerobic energy dissipation from FAA, and another $35 \%$ from protein amino acids.
\end{abstract}

\section{INTRODUCTION}

Fluctuations in the size of adult populations of fishes are largely believed to be determined by changes in the mortality in the egg, larval and juvenile stages (Hunter 1981, Houde 1987, 1989). Studies on larval survival have focused mainly on 3 mechanisms: predation pressure, dispersal of the pelagic embryo to suitable habitat, and food availability at first feeding (Baily \& Houde 1989, Cushing 1990). Metabolic capacity of the developing larvae is a critical factor to the latter mechanism. It is generally accepted that fish larvae require a continuous supply of suitable prey, and a match between the fish larvae and their planktonic prey has been suggested to be a crucial factor for larval survival at first feeding (Hjort 1914, Cushing 1990). However, the factors that determine the suitability of the feed are still not known (Houde 1987, Lasker 1987). Lipids, especially the poly-unsaturated fatty acids of the $n-3$ and $n-6$ series, have been implicated as a key to survival and growth of the fish larvae at first feeding (Watanabe et al. 1983, Henderson \& Sargent 1985). The high content of free amino acids (FAA) that is typically found in marine invertebrates and plankton, has recently been addressed in the discussion on nutrient requirements for the fish larvae at first feeding (Fyhn 1989, 1990). It is noteworthy that pelagic eggs of marine fishes contain a large pool of FAA at fertilization (Fyhn \& Serigstad 1987, Rønnestad 1990, Finn et al. 1991). The FAA pool is established in the pelagic egg during the final maturation as a means of inducing an osmotic influx of water to swell the oocyte before ovulation and spawning (Thorsen \& Fyhn 1991). Consistently, a decline in the FAA pool is seen and combined metabolic and biochemical data from cod (Fyhn \& Serigstad 1987), turbot (Rønnestad et al. 1992) and Atlantic halibut (Fyhn 1989, 1990, Finn et al. 1991), are mutually supportive and suggests that FAA are important as fuels in the energy dissipation of the developing larvae. Since the pattern of nutrient use during pre- 
feeding stages may infer the requirements when the larvae commence exogeneous feeding, a study on lemon sole was initiated to further examine the potential energetic function of FAA during the early life stages of marine fish larvae.

Lemon sole Microstomus kitt Walbaum is an important commercial fish, especially in British waters (Rae 1965). The species also has a potential for aquaculture and may complement Atlantic halibut and other flatfishes in duo-culture systems. Although some knowledge exists about the fisheries-related life history of lemon sole, the development of the eggs and larvae has hitherto only been rudimentarily described (see review by Russel 1976). Thus, one of the purposes of this study was to provide a more detailed morphological description of the early stages of lemon sole, thus enabling us to relate biochemical and physiological events to recognisable embryonic stages.

Similar to most other temperate marine fishes lemon sole produces large numbers of small pelagic eggs. These eggs can be considered as a semi-closed system permitting exchange of respiratory gases and heat, but only negligible amounts of water and solutes (Potts \& Rudy 1969, Rudy \& Potts 1969, Mangor Jensen 1987. Riis-Vestergaard 1987). The loss of FAA from the marine teleost embryo is minimal (Rønnestad 1992). The decreasing size of the FAA pool during development thus results from metabolic turnover of the amino acids in the embryonic free pool (Fig. 1). Assuming a fully aerobic metabolism 2 pathways are open for the removal of FAA. They may be catabolized ( $B$, Fig. 1), with the production of ammonia and consumption of oxygen, or be polymerized (C, Fig. 1) which implies an

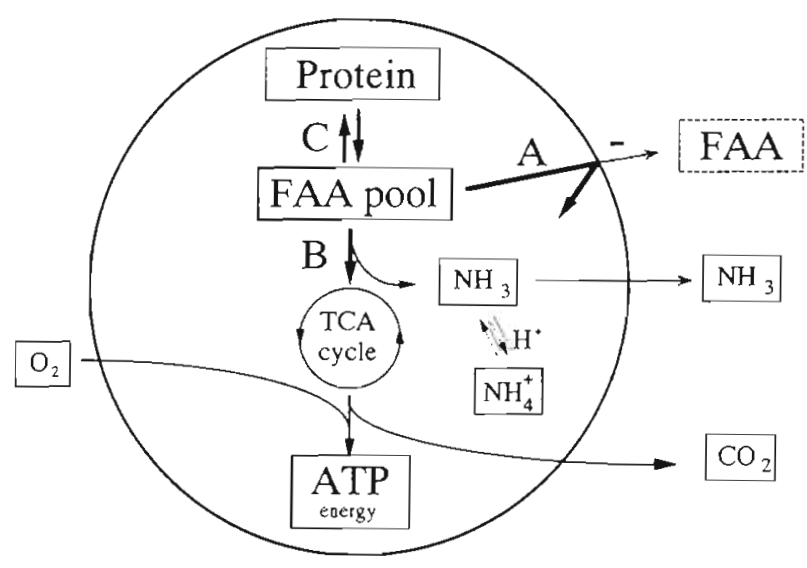

Fig. 1. A model of metabolic turnover of the pool of free amino acids (FAA) found in marine pelagic fish eggs and larvae. The processes are stoichiometrically related and can be determined through quantitative analysis of the individual parameters. (A) Efflux of intact FAA; (B) catabolism to yield ATP; (C) polymerization into body protein increase in the body protein content. Since both processes are stoichiometrically related to the amounts of FAA removed, the specific pathway of removal can be determined through quantitative analysis. Such data have been compiled in the present study for lemon sole, and the results are discussed in relation to the nutritional requirements of the developing larvae up to the point of first feeding in the ocean.

\section{MATERIALS AND METHODS}

Four series of eggs (A to D) were obtained from separate females. Series A consisted of a single batch of developing eggs and larvae. This series was used for energetic calculations and biometric measurements. The 3 other series were studied in order to clarify details on respirometry during development.

Egg collection and incubation. Mature specimens of lemon sole Microstomus kitt were caught in Raunefjorden, near Bergen, Norway, in May 1991. Eggs were stripped from the females, fertilized with milt from 1 or 2 males and transferred to static aquaria $(8 \mathrm{l})$ for incubation at a temperature of $7.2 \pm 0.2^{\circ} \mathrm{C}$, a salinity of $34 \%$, and continuous light at an intensity of ca 200 lux. About $75 \%$ of the rearing water was exchanged every 1 to $2 \mathrm{~d}$ during the experimental period. No stirring or aeration was applied and the larvae were not fed during the experiments. All experiments and sampling work with live eggs and larvae were carried out in a cold room at 6 to $8^{\circ} \mathrm{C}$.

Egg and larval morphology. Samples of 30 eggs or larvae were collected at intervals for biometric measurements and characterization of morphological development by light microscopy (Leitz Dialux, 50 to $200 \times$ ). The measurements taken were (Series A) egg diameter, yolk length $(L)$ and height $(H)$, and total and standard length (from the head to the end of notochord) of the larvae post hatch. Egg volume was calculated from the egg diameter using the formula of a sphere while the yolk volume $\left(V_{y}\right)$ was calculated from $L$ and $H$ measurements by the formula for a prolate sphere $\left(V_{y}=\pi / 6 L^{2}{ }^{2}\right.$; Blaxter \& Hempel 1963, Cetta \& Capuzzo 1982). The characterization of morphological development and drawings were based on photographs of live specimens (Wild M5 dissecting microscope equipped with a Minolta 7000 camera, and an ocular micrometer).

Respirometry. Oxygen consumption and ammonia excretion were measured by closed respirometry (average test period $25 \mathrm{~h}$, range 21 to $30 \mathrm{~h}$ ) on groups of 20 to 30 eggs or 5 to 15 larvae using spherical glass vials (Quickfit FR:S) of 10 to $30 \mathrm{ml}$ calibrated volume as respirometers. Physically healthy eggs or larvae were carefully selected using a dissecting microscope. A 
total of 6 replicates and 4 blanks were used for each data point. The measurements were carried out in both darkness and light (ca 200 lux) at $7.2 \pm 0.2^{\circ} \mathrm{C}$.

Oxygen consumption ( $\dot{\mathrm{V}}_{\mathrm{O}^{2}}$, nmol ind. $\left.{ }^{-1} \mathrm{~h}^{-1}\right)$ was calculated according to the formula:

$$
\dot{V}_{\mathrm{O}_{2}}=\frac{\Delta p \mathrm{O}_{2} \alpha_{\mathrm{O}_{2}} V_{\mathrm{H}_{2} \mathrm{O}}}{N \Delta t}
$$

where $\Delta p \mathrm{O}_{2}=$ difference in oxygen tension readings (Radiometer oxygen electrode, model E-5046, and analyzer, model PHM 73) of the respirometer water between control and experimental groups at the end of the test period; $\alpha_{\mathrm{O}_{2}}=$ solubility of oxygen, calculated using the equations proposed by Green \& Carrit (1967) with modifications of Forstner \& Gnaiger (1983); $V_{\mathrm{H}_{2} \mathrm{O}}=$ respirometer water volume corrected for the volume of eggs or larvae; $N=$ no. of eggs or larvae; and $\Delta t=$ elapsed time in the respirometer.

The oxygen tension in the respirometer water was measured on samples collected by a gas-tight glass syringe and injected directly into the measuring chamber of the analyzer. $\Delta \mathrm{pO}_{2}$ was about $30 \mathrm{~mm} \mathrm{Hg}$ and in no cases did the oxygen tension of the respirometer water at the end of the measurement drop below $105 \mathrm{mmHg}$ (about $65 \%$ saturation).

Ammonia excretion $\left(\dot{V}_{\mathrm{NH}_{3}}\right.$ nmol ind.$\left.^{-1} \mathrm{~h}^{-1}\right)$ was calculated according to the following formula:

$$
\dot{V}_{\mathrm{NH}_{3}}=\frac{\Delta\left[\mathrm{NH}_{3}\right] V_{\mathrm{H}_{2} \mathrm{O}}}{N \Delta t}
$$

where $\Delta\left[\mathrm{NH}_{3}\right]=$ difference in total ammonia concentration of the respirometer water between control and experimental groups and other symbols as in Eq. 1. Ammonia concentration in the respirometer water was measured in triplicate $(2 \mathrm{ml})$ according to the method of Bower \& Holm-Hansen (1980).

Analytical procedures. Pooled samples of 40 eggs ( 6 replicates) or 5 to 30 larvae ( 3 replicates) were taken regularly during development and extracted in $500 \mu \mathrm{l}$ (eggs) or $250 \mu \mathrm{l}$ (larvae) of $6 \%$ (final concentration) trichloroacetic acid (TCA) in cryotubes for at least $24 \mathrm{~h}$ prior to analysis. After centrifugation $(10000 \times g)$, the supernatant was used for analysis of FAA and accumulated ammonia, and the precipitated eggs or larvae were used for protein determination. FAA content was determined on an automatic amino acid analyzer (Chromaspek J 180, Hilger Analytical), whereas protein was determined by the method of Lowry et al. (1951) using the micro modification by Rutter (1967). Accumulated ammonia was determined as described by Fyhn \& Serigstad (1987) but using the modified salicylate-hypochlorite method of Bower \& HolmHansen (1980)

Statistical significance was tested by 1 -way single classification analysis of variance (ANOVA) using a
$5 \%$ level of significance. Regression lines were fitted by the method of least squares.

\section{RESULTS}

\section{Morphology and biometry}

The lemon sole larvae developed with low mortality to more than $30 \mathrm{~d}$ post fertilization, confirming the view of earlier workers that this species is relatively easy to rear (M'Intosh 1891, Heincke \& Ehrenbaum 1900 ). At a rearing temperature of $7.2^{\circ} \mathrm{C}$, first cleavage occurred 7 to $8 \mathrm{~h}$ post-fertilization. This was followed by rapid cell divisions until the blastodisc was formed at about 27 h (Day 1.1; Fig. 2). Gastrulation and epiboly was complete by Day 5. Beating of the heart was first observed on Day 9 and hatching occurred on Day 13. The newly hatched larva was pigmented along the fin margin and on the yolksac, its eyes were unpigmented, the gut was straight and morphologically undifferentiated, and both mouth and anus were closed (Fig. 2). Immediately after hatching the yolksac had a prolate shape and became more elongated with development. Near the time of final yolk absorption, the remaining yolk was located adjacent to the looped part of the gut. With increasing yolk resorption the larva showed a characteristic ventral concavity (Fig. 2). Eye pigmentation started on Day 19 and was complete by Day 22. The transition of the gut from a straight to a coiled tube was also initiated on Day 19 and was complete by Day 22. The mouth was open with movable jaws on Day 22. Based on these observations the lemon sole larva appeared ready to commence exogenous feeding by Day 22 post fertilization at $7.2^{\circ} \mathrm{C}$.

The average egg diameter on Day 1 post fertilization was $1.30 \pm 0.03 \mathrm{~mm}$, corresponding to a volume of 1.16 $\pm 0.08 \mu \mathrm{l}$ (Fig. 3). The egg diameter remained constant until the last day before hatching when it was slightly but significantly increased to $1.34 \pm 0.03 \mathrm{~mm}$, corresponding to a volume of $1.26 \pm 0.08 \mu \mathrm{l}(\mathrm{p}<0.05)$. Upon emergence from the egg the larval standard length was $3.91 \pm 0.18 \mathrm{~mm}$ (total length $4.01 \pm 0.20 \mathrm{~mm}$ ), increasing to $6.06 \pm 0.20 \mathrm{~mm}(6.28 \pm 0.21 \mathrm{~mm}$ total length) by Day 25. No further increase in standard length occurred after Day 25.

At fertilization the yolk volume was $1.05 \pm 0.08 \mu \mathrm{l}$ (Fig. 3). No significant decrease in yolk volume occurred prior to epiboly (Day 5), but thereafter yolk resorption proceeded gradually with 55 to $60 \%$ occurring prior to hatch, reaching 96 and $99 \%$ completion by Day 19 and 23 post fertilization respectively. Thus, only a few percent of the yolk mass remained when the larvae seemed ready to commence exogenous feeding 


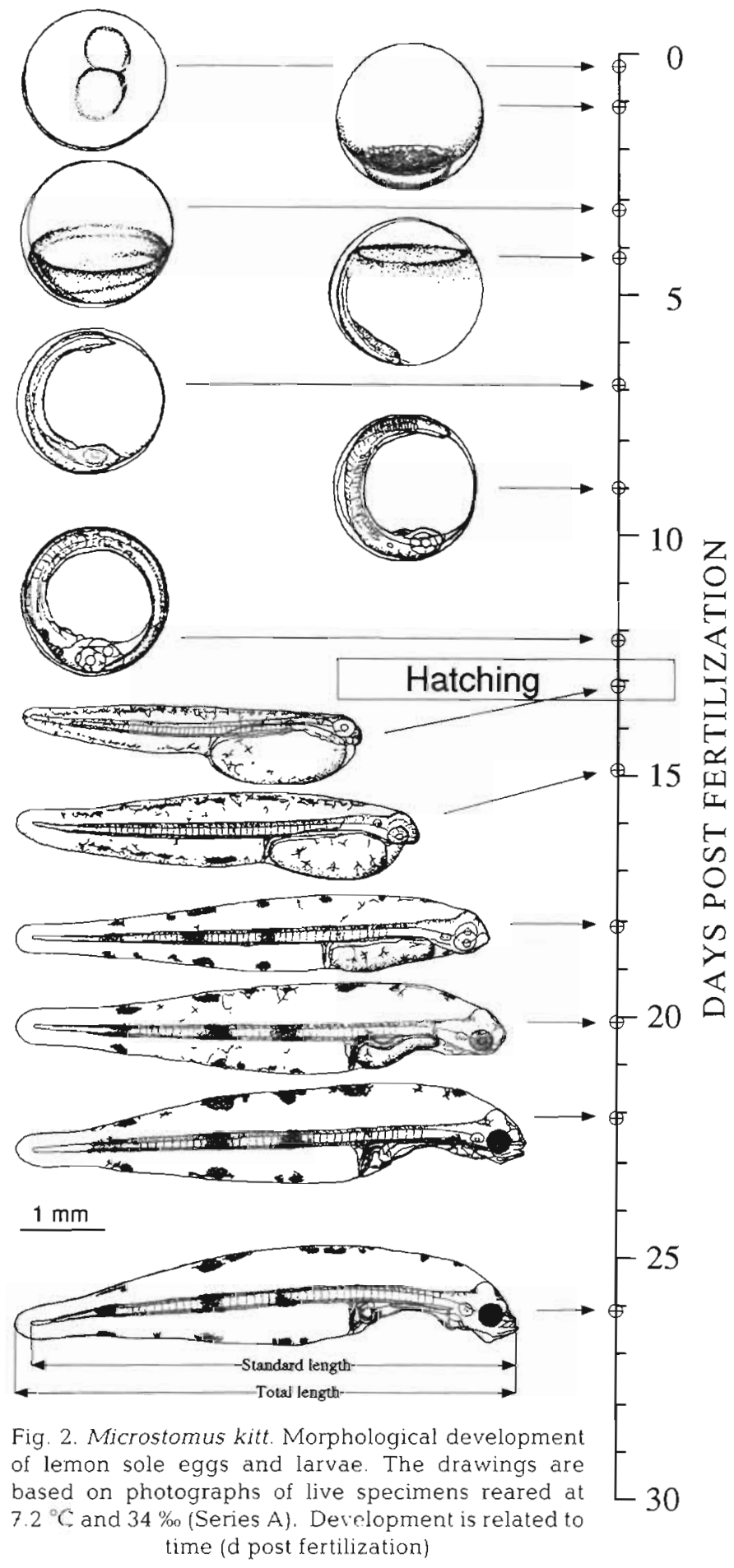

\section{Respirometry}

The rate of oxygen uptake increased gradually during the egg stage and levelled off following hatch at ca 2 nmol ind ${ }^{-1} \mathrm{~h}^{-1}$ (Fig 4). The data variance increased markedly during the larval stage. No consistent difference was found in the rate of oxygen uptake

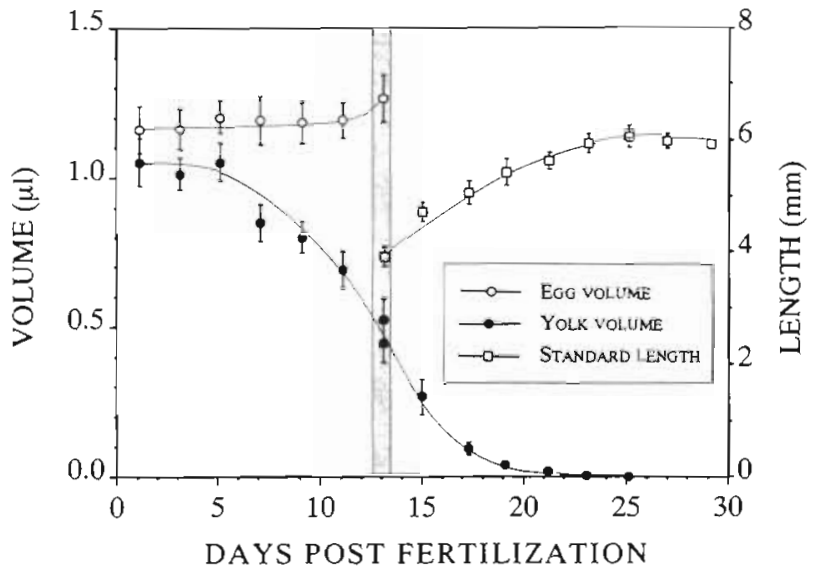

Fig. 3. Microstomus kitt. Yolk volume, egg diameter and standard length of developing lemon sole embryos reared at $7.2^{\circ} \mathrm{C}$ (Series A). Each data set represents the mean ( \pm SD) of ineasurements on 30 individuals

between light or dark test conditions. There was no notable increase in the uptake rate correlated with hatching or apparent readiness for exogenous feeding. After hatching the data from Series B was significantly lower than that of the other series at the same time.

The rate of ammonia excretion was low until Day 8 post fertilization whereupon the rate of excretion increased rapidly to about $0.5 \mathrm{nmol}$ ind $^{-1} \mathrm{~h}^{-1}$ just before hatching (Fig. 5). During the first $2 \mathrm{~d}$ after hatching, data from Series $B$ and $C$ showed an excretion rate in the range of 0.6 to $1.0 \mathrm{nmol}$ ind.-1 $\mathrm{h}^{-1}$. The excretion rate thereafter stabilized at $0.35 \mathrm{nmol}$ ind ${ }^{-1} \mathrm{~h}^{-1}$. No consistent difference was observed between the 4 series of eggs or between light and dark treatments. Data from Series $D$ indicated that the excretion rate remained stable up to Day 30 after fertilization.

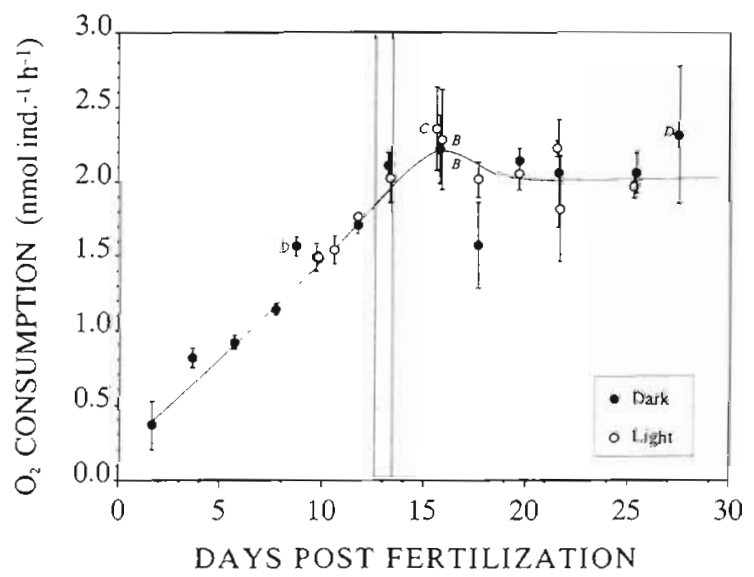

Fig. 4. Microstomus kitt. Oxygen uptake under light and dark conditions in developing eggs and larvae of lemon sole (Series A to D). The data are given as mean ( \pm SD) of 6 to 8 replicates using pooled samples of 20 to 30 eggs or 10 to 15 larvae 


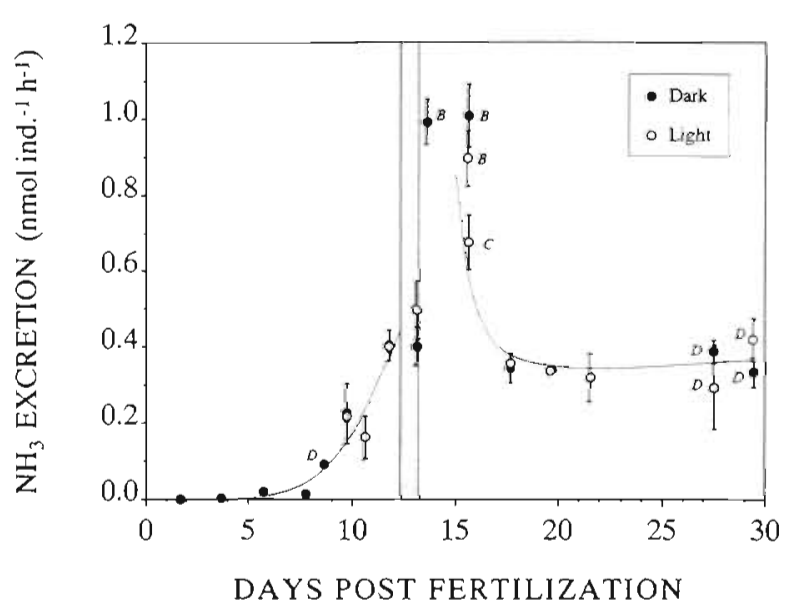

Fig. 5. Microstomus kitt. Ammonia excretion under light and dark conditions in developing eggs and larvae of lemon sole (Series A to D). Sampling as in Fig. 4

\section{Biochemistry}

During the first day of development, the lemon sole eggs contained $27.6 \pm 1.6 \mathrm{nmol}$ of ammonium, and gradually accumulated an additional $13 \mathrm{nmol}$ during the egg stage (Fig. 6). After hatching, larval ammonium content decreased by about $15 \mathrm{nmol}$ ind $^{-1}$ during the first day $\left(0.63 \mathrm{nmol}\right.$ ind.$\left.^{-1} \mathrm{~h}^{-1}\right)$, followed by about $10 \mathrm{nmol}$ ind $\mathrm{d}^{-1}$ during the next $3 \mathrm{~d}\left(0.15 \mathrm{nmol}\right.$ ind.$\left.^{-1} \mathrm{~h}^{-1}\right)$ and another $10 \mathrm{nmol}$ ind ${ }^{-1}$ during the following $11 \mathrm{~d}$ (0.04 nmol ind $\left.\mathrm{n}^{-1} \mathrm{~h}^{-1}\right)$.

A total FAA pool of $134 \pm 11.3 \mathrm{nmol}$ ind $^{-1}$ was found in the newly spawned lemon sole eggs (Fig. 7). No significant changes occurred in the pool size prior to epiboly, but about $75 \mathrm{nmol}$ ind ${ }^{-1}(56 \%)$ had disappeared prior to hatch. When the yolk was totally

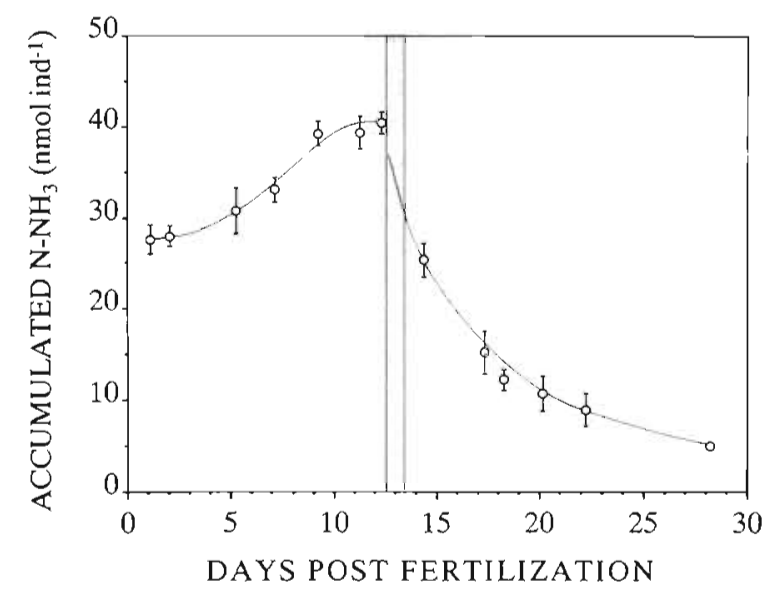

Fig.6. Microstomus kitt. Accumulated ammonium in developing embryos of lemon sole (series A). The data are presented as mean $( \pm \mathrm{SD}$ ) of 6 samples of 40 pooled eggs, or 3 samples of 15 to 30 pooled larvae

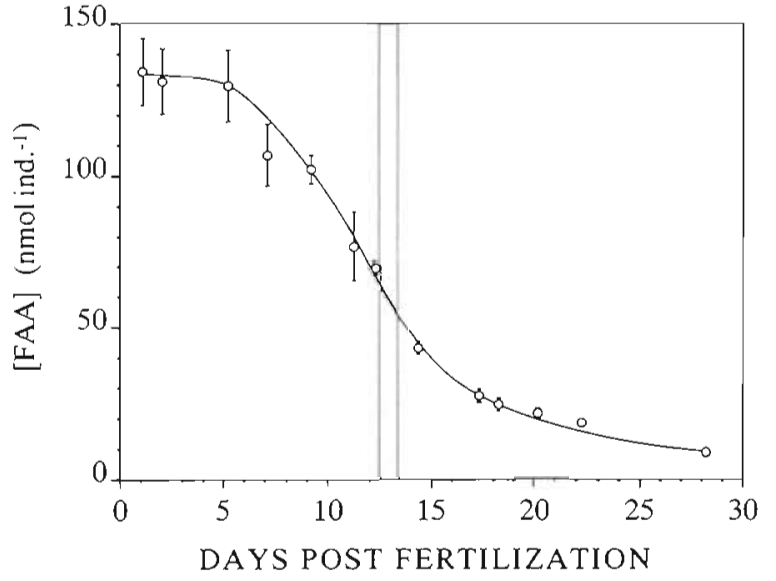

Fig. 7. Microstomus kitt. Total content of free amino acids ( $F A A ;$ mean $\pm S D$ ) in developing eggs and larvae of lemon sole (Series A). Sampling as in Fig. 6

resorbed (Days 23 to 25) the FAA pool had decreased to about $15 \mathrm{nmol}$. A highly significant linear correlation existed between the yolk volume $\left(V_{\mathrm{y}}, \mathrm{nl}\right)$ and the content of FAA (C $C_{\mathrm{FAA}}$, nmol) $\left(C_{\mathrm{FAA}}=108.19 V_{Y}+7.16\right.$; $\left.\mathrm{I}^{2}=0.986, \mathrm{p}<0.001\right)$.

Serine, alanine, leucine and lysine, followed by valine, glutamic acid and isoleucine, quantitatively dominated the FAA pool of the newly spawned lemon sole eggs (Fig. 8). Essential amino acids (arginine, histidine, isoleucine, leucine, lysine, methionine, phenylalanine, threonine and valine; Wilson 1985) and nonessential amino acids made up 56 and $44 \%$ of the FAA pool respectively.

The content of most FAA decreased as development progressed. In contrast, the amount of phosphoserine increased slowly while the amino acid analogue taurine was present in a constant amount of $4.5 \pm 0.3$ nmol ind.$^{-1}$ regardless of the developmental stage analysed. The content of tyrosine did not decrease markedly prior to Day 22. On the last day of analysis (Day 28 post fertilization) taurine and phosphoserine together accounted for about $60 \%$ of the larval tissue pool of FAA. The decrease in the amount of essential amino acids accounted for about $55 \%$ of the total decrease in the FAA pool during the egg stage suggesting that no sparing of essential versus nonessential amino acids occurred during development in the lemon sole embryo.

The protein content increased significantly $(p<0.001)$ by about $4 \mu \mathrm{g}$ during the egg stage (Fig. 9). A decrease of 12 to $14 \mu \mathrm{g}$ of protein occurred at hatching correlated with shedding of the chorion and the perivitelline fluid colloids. The larval protein content decreased progressively after hatching. On Day 28 after fertilization the larval protein content was significantly lower $(p<0.001)$ than on Day 14 . 


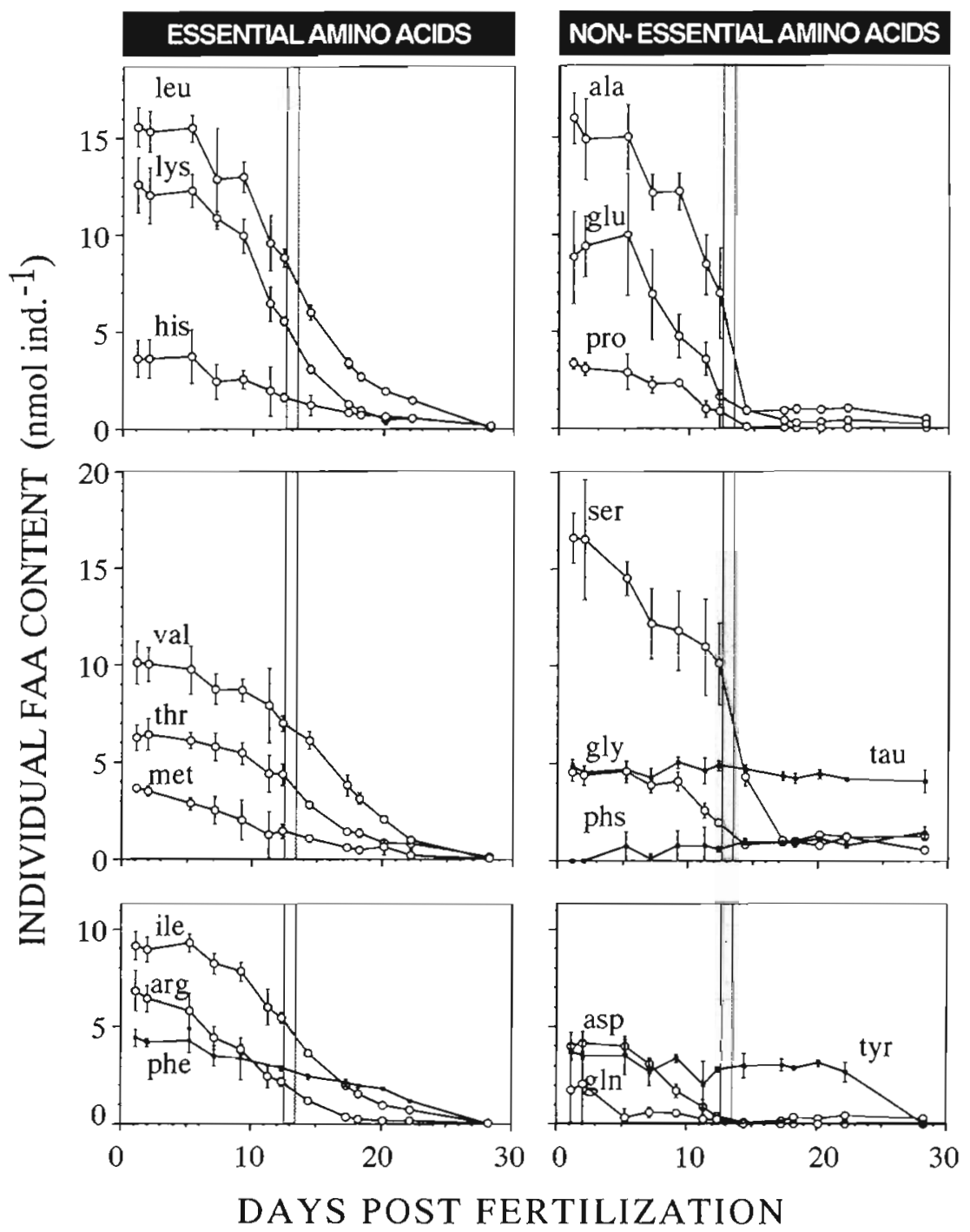

Fig.8. Microstomus kitt. Individual free amino acid content (mean \pm SD) in developing eggs and larvae of lemon sole (Series A). leu: leucine; lys: lysine; his: histidine; ala: alanine; glu: glutamic acid; pro: proline; val: valine; thr: threonine; met: methionine; ser: serine; gly: glycine; phs: phosphoserine; tau: taurine; ile: isoleucine; arg: arinine; phe: phenylalanine; asp: aspartic acid, tyr: tyrosine. Sampling as in Fig. 6

\section{DISCUSSION}

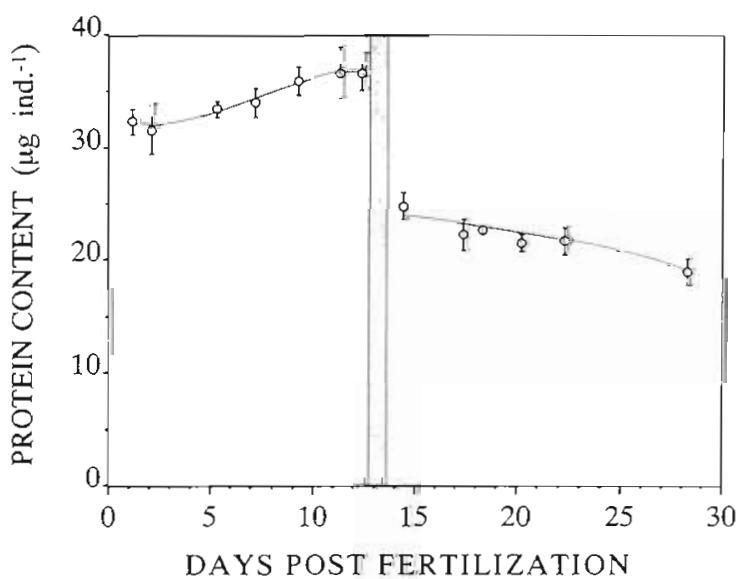

Fig. 9. Microstomus kitt. Total protein content in developing eggs and larvae of lemon sole (Series A). Sampling as in Fig. 6
Composition of the FAA pool in the newly fertilized egg of lemon sole is consistent with findings for other fishes with pelagic eggs (Fyhn 1990, Rønnestad 1990 , Thorsen \& Fyhn 1991). Similarly, the decrease in the size of the FAA pool during development agrees with past studies on other marine fish eggs (Fyhn 1989, 1990, Finn et al. 1991, Rønnestad et al. 1992), although both the absolute content and the timing of the sequence is different in lemon sole. The pattern of ammonia accumulation during the egg stage conforms with the situation in cod Gadus morhua (Fyhn \& Serigstad 1987) and turbot Scophthalmus maximus (Rønnestad et al. 1992). The ammonia accumulation may reflect a buoyancy regulation of pelagic marine fish eggs (Fyhn 1992). The following discussion focuses on the use of FAA as a fuel. for the developing lemon sole, and the nutritional requirements before commencing exogeneous feeding. 


\section{Calculations}

Based on the relative composition of the disappearing FAA pool in the developing lemon sole embryo, an 'average amino acid' in the pool would have a formula of $\mathrm{C}_{4.83} \mathrm{H}_{10.22} \mathrm{O}_{2.39} \mathrm{~N}_{1.34} \mathrm{~S}_{0.03}$ and a molecular weight of 126.3. Since ammonia is the main nitrogenous end product of aerobic amino acid catabolism (van Waarde 1983, 1988, Campbell 1992) oxidation of this 'average amino acid' can be stoichiometrically balanced as follows:

$$
\begin{aligned}
& \mathrm{C}_{4.83} \mathrm{H}_{10.22} \mathrm{O}_{2.39} \mathrm{~N}_{1.34} \mathrm{~S}_{0.03}+5.24 \mathrm{O}_{2} \\
\Rightarrow & 4.83 \mathrm{CO}_{2}+3.10 \mathrm{H}_{2} \mathrm{O}+1.34 \mathrm{NH}_{3}+0.03 \mathrm{SO}_{4}
\end{aligned}
$$

Thus, for lemon sole embryo $5.24 \mathrm{~mol}$ of $\mathrm{O}_{2}$ are necessary to catabolize $1 \mathrm{~mol}$ of the disappearing FAA with the release of $1.34 \mathrm{~mol}$ of $\mathrm{NH}_{3}$. Similarly, it can be calculated that $108.3 \mathrm{~g}(126.3-18.0)$ of body protein could be synthesized per mol of disappearing FAA.

In metabolic studies the respiratory quotient $(R Q$, mol $\mathrm{CO}_{2}$ produced per mol $\mathrm{O}_{2}$ consumed) represents a well-known concept for estimation of the energy substrates involved. In addition, the nitrogen quotient ( $N Q$, mol $\mathrm{NH}_{3}$ produced per $\mathrm{mol} \mathrm{O}_{2}$ consumed) represents another useful but less known ratio that, together with $R Q$, allows exact calculation of the energy substrates involved (Gnaiger 1983). The average $N Q$ for pure protein catabolism is $0.27 \pm 0.01$ as measured from the catabolism of whole body proteins from a variety of sources (Gnaiger 1983). This average compares favourably with the value of 0.26 calculated from the above Eq. 3. When increasing amounts of nonnitrogenous compounds (i.e. lipids or carbohydrates) are catabolized, the ratio tends towards zero. The exact fraction of the total energy dissipation that is provided from catabolism of amino acids depends on whether lipids or carbohydrates are utilized concurrently. Stoichiometry shows that for a given NQ a concurrent oxidation of carbohydrates will result in a lower fraction of amino acids (see Gnaiger 1983 for calculation procedure) compared to concurrent oxidation of lipids. Based on the NQ values calculated from the present measurements, the theoretical range of amino acid contribution to the aerobic energy dissipation is presented in Table 1.

The data also allow quantitative balancing of substrates and end products with respect to the nitrogen metabolism as shown by Eq. 3 and Fig. 1. Via stoichiometry, one can calculate the amount of ammonia that would result from aerobic catabolism of the disappearing FAA ( $B$, Fig. 1) and compare it with the measured ammonia production. Further, it is possible to calculate the amounts of oxygen necessary to catabolize the FAA that have been used for energy metabolism according to the measured ammonia production in the
Table 1. Microstomus kitt. Nitrogen quotient (NQ) and range of percent of total aerobic energy dissipation derived from amino acid (AA) catabolism in developing eggs and larvae of lemon

\begin{tabular}{|c|c|c|}
\hline Day & $N Q$ & Energy from AA (\%) \\
\hline $0 \rightarrow 1$ & $0^{2}$ & $0^{\mathrm{a}}$ \\
\hline $2 \rightarrow 3$ & $0^{\mathrm{a}}$ & $0^{\text {a }}$ \\
\hline $4 \longrightarrow 5$ & 0.08 & $25-48$ \\
\hline $6 \rightarrow 7$ & 0.10 & $32-54$ \\
\hline $8 \rightarrow 9$ & 0.14 & $45-68$ \\
\hline $10 \longrightarrow 11$ & $0.25^{b}$ & $90-96^{b}$ \\
\hline $12 \longrightarrow 13$ & $0.33^{b}$ & $100^{b}$ \\
\hline $14 \longrightarrow 15$ & 0.17 & $56-77$ \\
\hline $16 \longrightarrow 17$ & 0.13 & $41-65$ \\
\hline $18 \rightarrow 19$ & 0.13 & $41-65$ \\
\hline $20 \longrightarrow 21$ & 0.15 & $48-71$ \\
\hline $22 \longrightarrow 23$ & 0.15 & $48-71$ \\
\hline $24 \longrightarrow 25$ & 0.16 & $52-74$ \\
\hline $26 \longrightarrow 27$ & 0.16 & $52-74$ \\
\hline $28 \longrightarrow 29$ & 0.16 & $52-74$ \\
\hline \multicolumn{3}{|c|}{ Undetectable levels of ammonia production } \\
\hline
\end{tabular}
sole. See text for calculation procedure and assumptions

embryo during the egg and yolksac larval stage. These values can then be compared with the measured oxygen consumption of the lemon sole embryos during the same periods. Any shortage must be accounted for by a non-nitrogenous substrate. One can also calculate the amount of protein that would result from polymerization of the disappearing FAA (C, Fig. 1). These calculations and comparisons have been summarized in Fig. 10. At periods when the ammonia production exceeds what can be explained by catabolism of FAA, amino acids from the protein pool have been included in the budget.

\section{Utilization of FAA as nutrients}

The undetectable ammonia production (Figs. $5 \& 6$ ) and the corresponding low $N Q$ found during the first days after fertilization (Table 1) together with the results from the calculations shown in Fig. 10 suggest an aerobic energy dissipation based on non-nitrogenous fuels during this period. Similar findings of low $N Q$ values are also characteristic for the early stages of the Atlantic halibut (Finn et al. 1991) and turbot (Rønnestad et al. 1992). Since both the yolk volume and the total FAA content remained constant until completion of epiboly in lemon sole, the embryo may utilize nonnitrogenous energy substrates from cytoplasmic stores (e.g. glycogen granules, dispersed lipids) during these early developmental stages. Previously, carbohydrates have been suggested as the main energy substrate for the initial period of development after fertilization in 


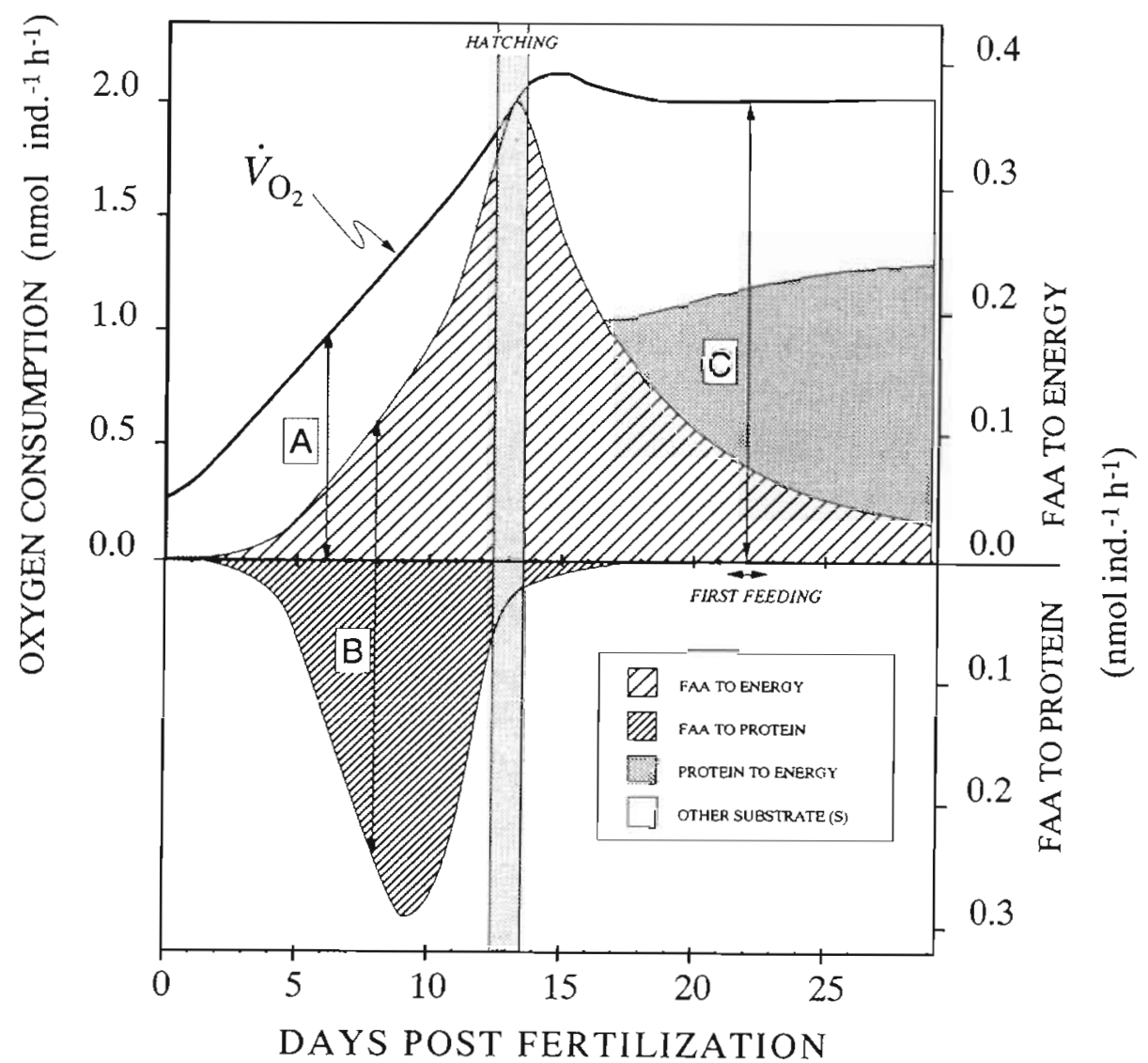

Fig. 10. Microstomus kitt. A proposed scheme for utilization of FAA in developing eggs and larvae of lemon sole at $7.2^{\circ} \mathrm{C}$. Arrow A shows the rate of oxygen uptake, which at this point is equal to about $1 \mathrm{nmol} \mathrm{O}_{2}$ ind $^{-1}$ $h^{-1}$ FAA accounts for about $40 \%$ of the oxygen uptake, while other non-nitrogenous substrate(s) accounts for the remaining. Arrow $B$ indicates the total amount of FAA disappearing from the pool. At this point about $0.12 \mathrm{nmol}$ ind $^{-1}$ $\mathrm{h}^{-1}(40 \%)$ are utilized as an energy substrate, and about 0.25 nmol ind $^{-1} \mathrm{~h}^{-1}(60 \%)$ are polymerized into body proteins. Arrow $\mathrm{C}$ indicates the time of first feeding. At this stage catabolism of FAA accounts for $20 \%$ of the oxygen uptake, while amino acids from protein account for another $35 \%$. See text for further explanations marine fish embryos (Cetta \& Capuzzo 1982, Planas et al. 1992). In the early stages of turbot development, glycogen has been reported as the major carbohydrate energy source (Planas et al. 1992). Developing oocytes of loach Misgurnus fossilis show a marked increase in the activity of glycolytic enzymes supporting that carbohydrates supply all the energy up to fertilization. (Boulekbache 1981). In red drum Sciaenops ocellata lipids are reported to supply virtually all of the catabolic demand during the egg stage (Vetter et al. 1983).

The yolk syncytium layer is formed in teleost fish eggs during epiboly, and is a specialized tissue responsible for endocytotic yolk resorption (Heming \& Buddington 1988). According to the same authors, the rate of yolk resorption is a function of surface area and endocytotic activity. In marine fish embryos, the surface area of the yolk syncytium layer ideally reaches its maximum at completion of epiboly when it becomes equal to the yolk surface area (Heming \& Buddington 1988). After epiboly the yolk syncytium layer progressively decreases due to utilization of the yolk material and osmotic loss of water to the ambient seawater (e.g Mangor-Jensen 1987), although the surface area may be temporarily altered by changes in geometrical shape. In the lemon sole embryo the slow decrease in yolk volume (Fig. 3) and FAA con- tent (Fig. 7), as well as the low ammonia production (Figs. $5 \& 6$ ) suggest that the endocytotic activity of the yolk syncytial layer is low until epiboly is complete. The later increase in yolk resorption rate probably results from increased endocytotic activity of the yolk syncytium, assisted by the onset of circulation as indicated by commencement of the heart beat (Day 9). The increased resorption rate would allow a faster transport of yolk nutrients and FAA from the syncytium layer to the developing embryonic tissues as demanded by the increasing metabolic rate during this period (Fig. 4). The concomitant decrease in the FAA pool and yolk volume of later developmental stages supports the idea that the yolk FAA are taken up by a non-selective, bulk flow mechanism such as endocytosis. Thus, before completion of epiboly, the strategy for utilization of the various energy substrates might simply be one of availability. Glycogen granules or dispersed lipids may readily be available to the cells as cytoplasmic inclusions, whereas the FAA are mainly found in the yolk compartment (Rønnestad \& Fyhn 1992) and need to be absorbed and distributed before being available for cellular metabolism in the embryo tissues.

After completion of epiboly the calculations shown in Fig. 10 and the $N Q$ data (Table 1) indicate that the 
increasing amounts of FAA which are entering the embryo from the yolk, are utilized both for energy dissipation and protein synthesis. A similar timing of events for the FAA uptake was also found for Atlantic halibut, although no increase in the protein content was found in this species, suggesting that all the FAA were utilized as an energy substrate (Fyhn 1989, Finn et al 1991). For lemon sole the calculations based on the ammonia production suggest that about $55 \%$ (41 nmol) of the disappearing FAA were available for polymerization into body protein during the egg stage. A protein synthesis of this order (about $4 \mu \mathrm{g}$ ) agrees with the actual measurements for body protein content (Fig. 9). During Day 7 FAA accounted for about $40 \%$ of the aerobic energy dissipation. This fraction increased to about $100 \%$ around hatching. At this time however, the energy budget of lemon sole can only be approximated, due to difficulties in the ammonia measurements in Series A. Using the data from the newly hatched larvae in Series B and $C$, the excretion rate of 0.6 to $1.0 \mathrm{nmol}$ ind $^{-1} \mathrm{~h}^{-1}$ suggests that FAA could fully account for all the energy dissipated. This is reflected in $N Q$ values of 0.25 to 0.33 during this period (Table 1 ).

About $2 \mathrm{~d}$ after hatching the amount of disappearing FAA could no longer account for all the ammonia produced by the lemon sole larvae. To make up for the discrepancy an additional amount of about $10 \mathrm{nmol}$ of amino acids, corresponding to about $1 \mu \mathrm{g}$ protein, needs to be recruited from the embryo before Day 22 post fertilization. A protein hydrolysis of this order is within the bounds of our measurements for protein content (Fig. 9). Thus, for the developing lemon sole embryo body proteins seem to serve as a temporary storage for amino acids taken from the free pool during the egg stage and recruited for energy purposes later in development. This may be analogous with the situation in the adult fish where proteins of the white muscle mass act as an energy reservoir during periods of prolonged starvation (Love \& Black 1990). It is noteworthy that the lemon sole larvae still possess about $10 \%$ of the yolk sac at the time when body proteins are recruited for energy purposes (Figs. $3 \& 10$ ). Possibly, the uptake rate of yolk nutrients by the diminished syncytium layer are below what is required by the growing embryo at this time.

An increase in swimming activity as part of a fixed behaviour pattern is seen when the fish larvae is ready to commence exogeneous feeding (Skiftesvik \& Huse 1987). This increase occured although no prey organisms were presented to the larvae. A peak in oxygen consumption rate is found during this period for unfed larvae of Atlantic cod (Serigstad 1987) and turbot (Rønnestad et al. 1992). However, no increase in the oxygen consumption was seen for the unfed larvae of lemon sole in the same period (Fig. 4). Further, no difference was found in the oxygen consumption rate of lemon sole larvae incubated under conditions of light or dark (Fig 4), as is the case for cod larvae (Serigstad 1987). Most teleost larvae are said to be visual planktivore feeders (Hunter 1981), but chemokinesis based on emanating amino acids and other metabolites from the prey organism has also been suggested as a cue for external feeding in marine fish larvae (Doving \& Knutsen 1992). Lemon sole larvae may be controlled by the latter mechanism so that light is not enough to initiate the feeding responses and the coupled increase in swimming activity and oxygen uptake rate.

Our data suggest that lemon sole larvae at the presumed time for onset of first feeding derive about $20 \%$ of their aerobic energy dissipation from FAA, and another $35 \%$ from protein bound amino acids. Thus in total, amino acids account for about $55 \%$ of the energy substrates. Similar calculations show that larvae of Atlantic halibut derive about $60 \%$ of their energy from FAA at the time just prior to first feeding with no contribution from protein (Rønnestad \& Naas 1992). It was shown that the latter dependence on amino acids seemed to apply whether the halibut larvae were in the endogenous or exogenous feeding mode. Data on cod larvae at first-feeding (Finn unpubl.) also show that between 50 to $70 \%$ of energy dissipation was due to amino acid catabolism. These reports contrasts the findings in turbot, (whose eggs contain an oil globule) where amino acids only seem to account for about $10 \%$ of their aerobic energy dissipation during this period (Ronnestad et al. 1992). Studies on other fish embryos that also contain an oil globule (Coryphaena hippurus: Ostrowski \& Divakaran 1991; Scianenops ocellata: Vetter et al. 1983) support the latter use of lipids as a main substrate.

It is evident that from this study and the literature that utilisation of energy substrates are species specific. Energy dissipation based on lipids seems to be important for those species whose eggs contain oil globules while amino acids play a more important role for those species whose eggs do not contain oil globules. These findings may have great implications for the nutritional requirements at the onset of first feeding

Acknowledgements. We are indebted to Maria Sula Evjen for keen analytical assistance. The study was supported by the Norwegian Fisheries Research Council. R.N.F. acknowledges support from the Royal Norwegian Council for Industrial and Scientific Research. E.P.G. acknowledges support from the Office of International Relations, University of Bergen, and the Department of Fisheries and Oceans, Pacific Biological Station, Nanaimo, British Columbia, Canada 


\section{LITERATURE CITED}

Baily, K., Houde, E. D. (1989). Predation on eggs and larvae of marine fishes and the recruitment problem. Adv. mar. Biol. 25: 1-83

Blaxter, J. H. S., Hempel, G. (1963). The influence of egg size on herring larvae (Clupea harengus L). J. Cons. int. Explor. Mer. 28: 211-240

Boulekbache, H. (1981). Energy metabolism in fish development. Am. Zool. 21: 377-389

Bower, C. E. Holm-Hansen, T. H. (1980). A salicylatehypochlorite method for determining ammonia in seawater. Can. J. Fish. Aquat. Sci. 37: 794-798

Campbell, J. W. (1992). Excretory nitrogen metabolism. In: Prosser, L. (ed.) Environmental and metabolic animal physiology. Wiley-Liss, New York, p. 277-324

Cetta, C. M., Capuzzo, J. M. (1982). Physiological and biochemical aspects of embryonic and larval development of the winter flounder (Pseudopleuronectes americanus). Mar. Biol. 71: 327-337

Cushing, D. H. (1990). Plankton production and year class strength in fish populations: an update of match/mismatch hypothesis. Adv. mar. Biol. 26: 249-293

Døving, K. B., Knutsen, J. A. (1992) Chemokinesis in marine fish larvae. In: Walther, B. T., Fyhn, H. J. (eds.) Physiology and biochemistry of marine fish larval development. Univ. Bergen, Bergen (in press)

Finn, R. N., Fyhn, H. J., Evjen, M. S. (1991). Respiration and nitrogen metabolism of Atlantic halibut eggs (Hippoglossus hippoglossus L.). Mar. Biol. 108: 11-19

Forstner, H., Gnaiger, E. (1983). Calculation of equilibrium oxygen concentration. In: Gnaiger, E., Forstner, H. (eds.) Polarographic oxygen sensors. Springer Verlag, Berlin, p. 322-333

Fyhn, H. J. (1989). First feeding of marine fish larvae: are free amino acids the source of energy? Aquaculture 80: $111-120$

Fyhn, H. J. (1990). Energy production in marine fish larvae with emphasis on free amino acids as a potential fuel. In: Mellinger, J. (ed.) Nutrition in wild and domestic animals. Karger, Basel, p. 176-192

Fyhn, H. J. (1992). Multiple functions of free amino acids during embryogenesis in marine fishes. In: Walther, B. T., Fyhn, H. J. (eds.) Physiology and biochemistry of fish larval development. Univ. Bergen, Bergen (in press)

Fyhn, H. J., Serigstad, B. (1987). Free amino acids as energy substrate in developing eggs and larvae of the cod Gadus morhua. Mar. Biol. 96: 335-341

Gnaiger, E. (1983). Calculation of energetic and biochemical equivalents of respiratory oxygen consumption. In: Gnaiger, E., Forstner, H. (eds.) Polarographic oxygen sensors. Springer Verlag, Berlin, p. 337-345

Green, E. J., Carritt, D. E. (1967). New tables for oxygen saturation of seawater. J. mar. Res. 25: 140-147

Heincke, F., Ehrenbaum, E. (1900). Eier und Larven von Fischen der Deutschen Bucht II. Die Bestimmung der schwimmenden Fischeier und die Methodik der Eimessungen. Wiss. Meeresunters. (Abt. Helgoland) 3: $127-332$

Henderson, R. J., Sargent, J. R. (1985). Fatty acid metabolism in fish. In: Cowey, C. B., Mackie, A. M., Bell, J. G. (eds.) Nutrition and feeding in fish. Academic Press, New York, p. $349-364$

Heming. T. A., Buddington, R. K. (1988). Yolk absorption in embryonic and larval fishes. In: Hoar, W. S., Randall D. J. (eds.) Fish physiology, Vol. XIA. Academic Press, New York, p. 408-138
Hjort, J. (1914). Fluctuations in the great fisheries of northern Europe viewed in the light of biological research. Rapp P.-v. Réun. Cons. int. Explor. Mer 20: 1-228

Houde, E. D. (1987). Fish early life dynamics and recruitment variability. Am. Fish. Soc. Symp. 2: 17-29

Houde, E. D. (1989). Subtleties and episodes in the early life of fishes. J. Fish Biol. 35A: 29-38

Hunter, J. R. (1981). Feeding ecology and predation of marine fish larvae. In: Lasker, R. (ed.) Marine fish larvae morphology, ecology and relation to fisheries. Washington Sea Grant Program, Univ. Washington Press, Seattle, p. $33-37$

Lasker, R. (1987). Use of fish eggs and larvae in probing some major problems in fisheries and aquaculture. Am. Fish. Soc. Symp. 2: 1-16

Love, R. M., Black, D. (1990). Dynamics of stored energy in north sea cod (Gadus morhua L.) and cultured rainbow trout (Salmo gairdneri Richardson). In: Mellinger, J. (ed.) Nutrition in wild and domestic animals. Karger, Basel, p. $193-202$

Lowry, O. H., Rosebrough, N. J., Farr, A. L., Randall, R. R. (1951). Protein measurement with the Folin phenol reagent. J. Biol. Chem. 193. 265-275

Mangor Jensen, A. (1987). Water balance in developing eggs of the cod Gadus morhua L. Fish Physiol. Biochem. 3: $17-24$

M'Intosh, W. C. (1891). Further observations on the lifehistories and development of the food and other fishes. A. Rep. Fish. Bd Scotl. 10: 317-342

Ostrowski, A. C, Divakaran, S. (1991). Energy substrates for eggs and prefeeding larvae of the dolphin Coryphaena hippurus. Mar. Biol. 109: 149-155

Planas, M., Labarta, U., Fernandez -Reiriz, M. J., Ferreiro, M. J., Munilla, R, Garrido, J. L. (1992). Chemical changes during early development in turbot (Scophthalmus maximus) eggs and larvae. In: Walther, B. T., Fyhn, H. J. (eds.) Physiology and biochemistry of fish larvae. Univ. Bergen, Bergen (in press)

Potts, W. T. W., Rudy, P. P. (1969). Water balance in eggs of the Atlantic salmon Salmo salar. J. exp. Biol. 50: 223-237

Rae, B. B., (1965). The lemon sole. Fishing News Books, London

Riis-Vestergaard, J. (1987). Physiology of teleost embryos related to environmental challenges. Sarsia. 72: 351-358

Ronnestad, I. (1990). Ammonia excretion, oxygen uptake, free amino acids and oil globule resorption during embryonic development of turbot (Scophthalmus maximus). In: Takeda, M., Watanabe, $T$ (eds.) The current status of fish nutrition in aquaculture. Tokyo Univ. Fisheries, Tokyo, p. $357-365$

Rønnestad, I. (1992). No efflux of free amino acids from yolksac larvae of Atlantic halibut (Hippoglossus hippoglossus) J. exp. mar. Biol. Ecol. (in press)

Ronnestad, L., Fyhn, H. J. (1992). Location of the free amino acid pool in marine fish embryos. Abstract A4.55. A. Meet. Soc. Exp. Biol., Lancaster, England, April 6-10, 1992. Soc. Exp. Biol., London, p. 23

Rønnestad, I, Fyhn, H. J., Gravningen, K. (1992). The importance of free amino acids to the energy metabolism of eggs and larvae of turbot (Scophthalmus maximus). Mar. Biol. (in press)

Rønnestad, I., Naas, K. E. (1992). Oxygen consumption and ammonia excretion in larval Atlantic halibut (Hippoglossus hippoglossus L.) at first feeding: a first step towards an energetic model. In: Walther, B. T., Fyhn, H. J. (eds.) Physiology and biochemistry of marine fish larval development. Univ. Bergen, Bergen (in press) 
Rudy, P. P., Potts, W. T. W. (1969). Sodium balance in eggs of the Atlantic salmon Salmo salar J. exp. Biol. 50: 239-246

Russel, F. S. (1976). The eggs and planktonic stages of British marine fishes. Academic Press, London

Rutter, W. J. (1967). Protein determination in embryos. In: Wilt, F. H., Wessels, N. K. (eds.) Methods in developmental biology. Academic Press, New York, p. 671-684

Serigstad, B. (1987). Oxygen uptake of developing fish eggs and larvae. Sarsia 72: 369-371

Skiftesvik, A. B., Huse, I. (1987). Behaviour studies of cod larvae. Sarsia 72: 367-368

Thorsen, A., Fyhn, H. J. (1991). Osmotic effectors during preovulatory swelling in marine fish. In: Scott, A. P., Sumpter, J. P., Kime, D. E., Rolfe, M. S. (eds.) Reproductive physiology of fish. Fish Symp. 91 - Univ. Sheffield, Sheffield, p. $312-314$

This article was presented by T. Kiorboe, Charlottenlund, Denmark van Waarde, A. (1983). Aerobic and anaerobic ammonia production by fish. Comp. Biochem. Physiol. 74 B: 675-684

van Waarde, A. (1988). Biochemistry of non-protein nitrogenous compounds in fish including the use of amino acids for anaerobic energy production. Comp. Biochem. Physiol. 91B: 207-228

Vetter, R. D., Houdson, R. E., Arnold, C. (1983). Energy metabolism in a rapidly developing marine fish egg, the red drum (Sciaenops ocellata). Can. J. Fish. Aquat. Sci. 40: $627-634$

Watanabe, T., Kitajima, C., Fujita, S. (1983). Nutritional value of live organisms used in Japan for mass propagation of fish: a review. Aquaculture 34: 115-143

Wilson, J. (1985). Amino acids and protein requirement of fish. In: Halver, J. (ed.) Nutrition and feeding in fish. Academic Press, London, p. 1-16

Manuscript first received: June 4, 1992

Revised version accepted: October 5, 1992 